REVISTA ANDALUZA DE ANTROPOLOGÍA

NÚMERO 17: ESTRATEGIAS SUBALTERNAS EN AMÉRICA LATINA: RECONFIGURANDO LA IDENTIDAD PARA ARTICULARSE A UN MUNDO GLOBAL. SUBALTERN STRATEGIES IN LATIN AMERICA: RECONFIGURING IDENTITY TO BE ARTICULATED TO THE GLOBAL WORLD.

SEPTIEMBRE DE 2019

ISSN 2174-6796

[pp. 146-154]

http://dx.doi.org/10.12795/RAA.2019.17.09

\title{
MARCOS ARÉVALO, JAVIER (2018). La Siberia extremeña en la voz de su gente (El etnógrafo y los informantes). Badajoz: Fundación CB y Universidad de Extremadura.
}

\author{
Juan Agudo Torrico \\ Universidad de Sevilla
}

La monografía presentada se trata de un trabajo formalmente muy denso, con 581 páginas de texto apretado y tamaño grande $(27 \mathrm{x} 21 \mathrm{cms}$.), con escasas imágenes y un mapa circunscrito a la comarca y ubicación de las poblaciones que la conforman.

El título refleja correctamente las intenciones del autor. Se trata de un trabajo, en el que significativamente no existe ninguna referencia bibliográfica, en el que autor apenas y no siempre se limita a realizar una breve reflexión introductoria sobre los contenidos de cada epígrafe (alimentación, juegos, rituales, etc...) para luego dejar hablar, extensamente, a los informantes. Lo cual, en nuestra opinión, como seguidamente referenciaremos, tiene sus pros y sus contras.

El trabajo se estructura propiamente en tres bloques temáticos, aunque formalmente sean seis capítulos. El primero ("Planteamientos metodológicos. El trabajo de campo: una experiencia personal") recoge la metodología empleada, pero sobre todo da cuenta de las razones de ser de este estudio y de sus peculiaridades, intercaladas con algunas reflexiones teóricas.

Se trata de un trabajo de campo realizado en 1994, publicado ahora, 24 años después. Las razones de su origen tienen mucho que ver con el proceso de "etnogénesis" que en territorios como la nueva comunidad autónoma extremeña se habían indicado con el restablecimiento del sistema democrático instaurado con la constitución de 1978 . Nuevas realidades políticas, generadoras o recuperadoras de unas identidades políticas que han de fundamentarse en unas identidades culturales a restablecer, redefinir o, sencillamente, crear. Y estas han de tener una determinada base territorial. En la página veintidós se explicita la razón que motiva la etnografía de la comarca de La Siberia “... 
solicitud de la Secretaría General Técnica de la Consejería de Cultura y Patrimonio de la Junta de Extremadura... para la realización de una investigación etnográfica sobre la Siberia Extremeña”.

Desde una perspectiva antropológica ya no se cuestiona que todo proceso de creación de una determinada "identidad cultural" nunca tendrá un origen "natural", esencialista e inalterable al paso del tiempo, o vinculado a cualquier falso imaginario racial. Todo lo contrario, son procesos fundamentados en unas bases históricas cambiantes con el transcurso del tiempo: en las motivaciones de sus orígenes, rasgos definitorios, extensión territorial, etc. El caso de España no deja de ser paradigmático. Cada periodo histórico ha tenido una articulación territorial diferente, con unas manifestaciones culturales dispares en sus lenguas, creencias, arquitecturas, paisajes, sistemas simbólicos, etc. De hecho, paradójicamente, la nueva estructuración territorial-cultural que se ha ido consolidando desde la segunda mitad del s. XX no es sino el resultado imprevisto de haber tratado de afianzar precisamente el proceso unitarista (político-cultural: estado nación) de la nueva españolidad burguesa surgida en el s. XIX, tratando de poner definitivamente fin al imaginario de lo que quedaba de los antiguos reinos medievales. La provincialización de 1833 acaba con los diversos y fragmentados territorios jurídicoadministrativos del antiguo régimen. Y, sin embargo, aquellos nuevos y arbitrarios límites provinciales han terminado por convertirse en límites culturales y jurídico-políticos con el subsiguiente proceso autonómico. Tanto es así que, según qué criterios se hubieran utilizado (organización religiosa, fiscal, señorial) la comarca de la Siberia hoy extremeña bien podría haber seguido siendo castellano-manchega como lo fuera en el pasado al depender de la sede episcopal toledana; como se refleja según el decir de sus habitantes en el origen y peculiaridades de algunos de sus rasgos culturales hasta el presente. Y lo mismo podríamos decir de otras comarcas vecinas de La Siberia como es el caso del Valle de Los Pedroches hoy andaluz (Córdoba), pero que hasta bien entrado el siglo XIX buena parte del mismo bajo influencia en muchos de sus aspectos administrativos y simbólicos de territorios extremeños; el propio condado de Belalcázar que ocupó buena parte del Valle de los Pedroches incluía como parte del mismo las poblaciones de Puebla de Alcocer y Herrera del Duque dentro de la comarca de la Siberia. Un vínculo entre extensos territorios localizados al sur de Badajoz y norte de Córdoba que aún se pone de manifiesto en muchos rasgos culturales compartidos: léxico, arquitectura, gastronomía, paisajes, etc.

El término etnogénesis aplicado a este proceso en el que se ve implicada la comarca es utilizado repetidamente por el autor, entremezclando las variables políticas (administración en el presente) y territoriales (naturales) como factores potenciadores. Aunque Javier Marcos emplea con frecuencia el término de "comarca natural" para referirse al conjunto de los 17 municipios que actualmente la componen, e incluso de 
manera más ambigua afirma a priori la existencia de una identidad étnica compartida, la etnografía resultante al decir del propio autor no parece tan contundente, ni a la hora de establecer sus límites, con poblaciones limítrofes de adscripción comarcal dubitativa.

En principio de aceptarse este proceso de etnogénesis (tal vez latente en la intencionalidad política de cartografiar etnográficamente estos territorios para dar a conocer, mostrar, unos rasgos culturales demostradamente compartidos), el nivel de referencia nunca puede ser la comarca, sino que tendría que ser la comunidad extremeña en la que se inserta. Aún en ámbitos coloquiales y no sólo político-culturalistas, el término de "comunidad" (conjunto de personas con unos intereses y/o rasgos culturales compartidos) es raro que lo encontremos aplicado a los ámbitos comarcales. Va a ser aplicado, referido al caso en cuestión, a los niveles de integración autonómico (comunidad extremeña, andaluza, castellano-manchega...) o bien a lo local, en referencia a las comunidades simbólicas que conforman nuestras poblaciones y en las que, pese a sus diferencias/desigualdades internas (al igual que ocurre en el nivel autonómico) se activa como sentimiento compartido en determinados contextos, imaginarios, simbólicos.

$\mathrm{Y}$, sin embargo, este nivel de referencia contrastiva, Extremadura, precisamente por su complejidad, apenas sí está presente. Se suele referenciar con frecuencia la influencia foránea de los territorios/cultura vinculada a las poblaciones castellano-manchegas de la antigua diócesis toledana a la que estuvo vinculada, pero no se nos dice, en contraposición, qué otros rasgos compartiría con el resto de Extremadura.

En el mismo sentido, en esta densa introducción se reitera su condición de "comarca natural", de la idiosincrasia de una identidad y rasgos peculiares comunes (tradiciones, gastronomía, rituales, derecho consuetudinario, etc.) pero nos queda la duda sobre si estos mismos rasgos son tan propios de la comarca o son en su inmensa mayoría compartidos con las comarcas igualmente extremeñas y circunvecinas de La Serena, Villuercas o Vegas Altas. E incluso más alejadas, de hecho, en lo que conozco y como he indicado, muchos de los rasgos descritos los podemos encontrar en la comarca cordobesa del Valle de los Pedroches, donde también al vino se le denomina de pitarra, ajoblanco, migas y relleno, forman parte de su gastronomía tradicional, nos aparece una arquitectura similar, léxico e incluso algunos de sus modelos festivo-ceremoniales son similares. Y aún podríamos aventurar hasta qué punto, cuestión sobre la que también reflexiona el autor, estos rasgos son propios de un determinado territorio o más bien de una vasta cultura rural-tradicional extendida por buena parte del territorio peninsular.

Sobre estas cuestiones, no menos significativo y lo que redunda en la arbitrariedad de los criterios que dan inicio a estos procesos de identificaciones colectivas, no deja de ser llamativo la peculiar y tardía (comienzos del siglo XX) denominación de "Siberia extremeña" con la que se le conoce hoy en día (en otros tiempos buena parte de sus poblaciones se redistribuían entre las comarcas vecinas y lo que quedaba se conocía 
como Los Montes), imposible por otra parte de rastrear en las motivaciones o razones históricas de su origen pese a esta cercanía temporal. Aunque sí parece existir consenso en el valor simbólico atribuible a dicha denominación, como analogía con la imagen creada de desolación con la que se asocia esta palabra por su vinculación con la Siberia rusa. La Siberia extremeña ha sido y es una comarca conformada por lugares aislados, de economía precaria y, en el pasado, vinculados a una imagen de sociedad caciquil fundamentada en la desigual distribución de la tierra y preponderancia del modelo latifundista. Actualmente se nos dice que ya es una denominación aceptada, en parte como consecuencia de la nueva redefinición política (todavía no jurídica en el caso de Extremadura) del hecho comarca a la hora de articular determinados servicios. Si bien, como anécdota no exenta de interés, aunque ya es aceptada la denominación de Siberia Extremeña como referencia comarcal, no lo es así la aplicación del gentilicio "siberiano", que sigue siendo rechazo por sus habitantes, atrincherados en el autorreconocimiento a lo sumo de sus gentilicios localistas.

Aunque la propia etnografía reflejada por el autor (frecuencia de los territoriospoblaciones más referenciadas, particularidades de algunos de los rasgos referenciados) parecen poner de manifiesto que existen al menos "dos comarcas" que han terminado por reestructurarse en la actual: los Montes (término que sigue aplicando en ocasiones al conjunto de ella), y el Llano. De igual modo, dos poblaciones reclaman la capitalidad (servicios, comercio, centralidad administrativa, importancia demográfica) de cada uno de estos territorios, Herrera del Duque (Los Montes) y Talarrubias (Los Llanos); y existen, según se desprende de los informantes y constantes alusiones, subáreas con fuertes singularidades: y estará siempre presente, como indica en repetidas ocasiones el propio autor, un fuerte localismo, bien motivado por la propia desvertebración que ha caracterizado a la comarca o, en sentido contrario, por la fuerte rivalidad habida entre poblaciones vecinas.

En la quiebra de esta desarticulación interna, así como del fundado imaginario de aislamiento del conjunto de la comarca, de tierra olvidada en la periferia tanto de Extremadura como de Castilla la Mancha, ha tenido mucho que ver, en palabras del autor, la Junta de Extremadura y la labor de las Diputaciones. Se trata, al menos en teoría, de articular y dotar de servicios a territorios aliados, cuando no marginalizados, pero también de conformar una autoconciencia de sí mismos como colectividades más allá de sus particularidades territoriales/localistas. Sería la prensión de esta etnografía comarcal, apoyando dichos presupuestos políticos-administrativos.

Todo lo dicho hace especialmente interesante este capítulo introductorio (al que añadir al menos los seis primeros epígrafes del capítulo III que le sigue), por lo que supone de reflexión, a contrastar en el futuro, sobre el proceso de construcción política de una "identidad territorial" comarcal, sin reconocimiento jurídico por hoy tal y como hemos 
indicado, pero que está jugando un destacado papel en el proceso de gestión administrativa y de servicios: sanitarios, judiciales, planes de desarrollo rural, etc. Quedaría por ver si ello también se materializa en otros procesos de identificaciones culturales.

Junto a esta imagen de la construcción identitaria fundamentada en el territorio, otra de las variables en las que el autor fundamenta las (breves) reflexiones teóricas que intercala, va a ser la pervivencia o no de la "cultura tradicional" (propiamente "rural-tradicional" en palabras de Javier Marcos) reflejada en la etnografía. En la multitud de temáticas abordadas en el capítulo de etnografía, con mucha frecuencia emplea la alocución "es/era" cada vez que describe/analiza alguna de ellas, aunque resulta evidente, y así lo recoge, que en la mayor parte de los casos se trata de valores, comportamientos y prácticas culturales que ya para aquellos años de 1994 estaban en declive cuando no, sencillamente, habían dejado de practicarse. Resulta significativo cómo pese a la considerable edad de buena parte de sus informantes, es frecuente que en sus narraciones no solo se remitan al pasado de lo que conocieron y ya no se hace, sino que con frecuencias emplean la construcción "haber oído decir" sobre prácticas o costumbres que ni siquiera ellos mismos habían vivido.

Aunque también resulta interesante apreciar qué rasgos de estas tradiciones han quedado en el pasado y cuales se mantienen en el presente. Poco queda de todo aquello relacionado con la tecnología preindustrial (oficios artesanos, sistemas de labranza y de transformación) empleada en la economía de subsistencia en la que se fundamentó el aprovechamiento de los parcos recursos ecológicos y agroganaderos disponibles; determinados valores y comportamientos sociales (padrinazgo, costumbres de noviazgo y boda); e incluso de la influencia directa y visibilidad sobre su organización social del orden jerarquizado impuesto por la desigual estructura basada en el latifundismo y caciquismo, otro de los referentes clave en el imaginario de lo que fue la vida en la comarca.

Pero otros rasgos se mantienen e incluso se reafirman como señas identitarias, emblemáticas, de la comarca/localidades; tal vez por su adaptación a nuevos usos sociales y a las nuevas lecturas que desde la nueva percepción patrimonialista se hace de ellos, como son los relacionados con la gastronomía y pervivencia e incluso reactivación de determinados festejos y rituales.

Y, sin embargo, estos planteamientos teóricos (tratados como hipótesis) muy a tener en cuenta, no parecen rebasar en su constatación, revisión o consecuencias los límites de capitulo inicial. Tal y como es recurrente escuchar en trabajos académicos tales como tesis o trabajos final de grados y master, los planteamientos teóricos no se aplican o no se perciben adecuadamente, en el devenir del análisis de la etnografía que le sigue. En gran medida porque como bien recoge el propio título de la obra y es intención del autor, en la etnografía que sigue los únicos protagonistas son los propios informantes. El capítulo 
III, intitulado sencillamente "Etnografía", es el núcleo clave y de indudable interés del conjunto del libro. Abarca desde la página 85 a la 461, organizado con una peculiar estructura de contenidos entrecruzados, aunque se ha pretendidos seguir el sistema básico de recoger, por este orden, las manifestaciones vinculadas con, en palabras del autor, la infraestructura (sistema tecnoeconómico, alimentación), organización social (sistema de clases, asociacionismo) y superestructura ideológica (creencias, prácticas festivoceremoniales, derechos consuetudinarios, mitos y leyendas). Un orden que, sin embargo, y tal vez por este intento de compartimentación cerrado, no siempre se consigue, dado como resultado temáticas que se entremezclan según el contexto en que se abordan, y por ello la reiteración a veces excesiva de frases introductorias o aclaratorias, e incluso de algunas interpretaciones; o, en sentido contrario, contradicciones en su interpretación según la mirada desde la que se aborde.

No se trata de un análisis/interpretación/valoración al uso académico/investigador en el que se plantea una temática y se contrasta o revisan sus contenidos/conclusiones a partir de los datos aportados por informantes y otras fuentes de documentación. Considero que no hay ni existe tal pretensión. Se trata, por el contrario, de una metodología caleidoscópica, de temáticas muy diversas y con frecuencia entremezcladas. Emigración, autopercepción del territorio y su vinculación con los proceso de identificación colectiva, conflictos y rivalidades localistas, arquitectura vernácula, tecnologías e industrias de trasformación, artesanías, caza y pesca, cultura pastoril, alimentación, asociacionismo y formas de sociabilidad, religión y religiosidad, festejos y rituales, prácticas vinculadas al ciclo de la vida, parentesco, sistema de herencia, literatura oral y leyendas y otros temas se intercalan, se estructuran en torno a 24 epígrafes y multitud de subepígrafes. El resultado es un maremágnum de información que pretende ser valiosa por sí misma (y lo es), sin que apenas medie el interlocutor que la ha recogido, dejando hablar extensamente a los informantes y delegando en el lector las interpretaciones.

En cada epígrafe Javier Marcos se limita, y no siempre, a realizar una somera presentación, más elaborada en aquellas cuestiones en las parece desenvolverse mejor por su bagaje como investigador (creencias y sistema devocional, rituales y festejos, tradición oral), pero bastante parca y confusas en otros casos (arquitectura, estructura socioeconómica). Luego se deja hablar a los informantes, con párrafos generalmente muy largos y consecutivos entre diferentes informantes, en ocasiones con contradicciones entre lo que se cuentan entre ellos.

Una metodología que en mi opinión tiene un factor positivo y otro no tanto. Lo más valioso es que las propias narraciones de los informantes tienen con frecuencia un gran valor en sí mismas, en su semántica, construcciones gramaticales, léxico, prioridades e información complementaria aportada, así como en las confusiones y olvidos que también se registran. Aunque esta riqueza en información queda inconclusa 
en sus significados cuando puede ser cuestionada por el más que probable precario conocimiento del informante sobre el tema preguntado (arquitectura, oficios artesanos y tecnologías empleadas en el pasado y ya solo citadas de oídas, imprecisiones en el uso del derecho consuetudinario en diferentes aspectos relacionados con sistemas de herencia o aprovechamiento de bienes comunales); faltando tal vez una mayor matización en sus detalles según variables como su aplicabilidad según sectores sociales (la imagen que se nos muestra es de sociedades locales bastante homogéneas una vez restada la élite terrateniente, y esto último siempre en pasado) e incluso de aplicarse la variable género. Tanto es así que cuando estas dos variables nos aparecen la información se enriquece notablemente, caso de la rica información sobre el sistema alimentario o de los matices localistas y según extensión de los predios en los sistemas de aprovechamiento de la tierra, o de todo lo relacionado con la caza y recolección de productos silvestres.

Ejemplo de lo dicho respecto a dispersión de información e incluso contradicción en las ideas dominantes que subyacen a lo largo del texto, sería el epígrafe que lleva por título "Eso de las clases aquí se ha terminado. Estratificación social". Explícitamente parece existir consenso entre todos los informantes en la desaparición de uno de los rasgos distintivos del pasado aplicable a toda la comarca, la fuerte polarización social entre un amplio sector jornalero y de pequeños propietarios y grandes hacendados que contralaban la vida sociopolítica de estas poblaciones. Pero sorprende que aun siendo así, pese a su condición de un pasado relativamente reciente y formar parte de una memoria todavía viva (1994), apenas se visualice lo que supuso este modelo de estructura social fuertemente desigualitaria, y que solo sea reiteradamente citado con escuetas y repetitivas alusiones a que existió sin más. Sólo algunos testimonios indirectos nos dan cuenta de lo que debió ser su influencia en comportamientos y modos de vida. Y sin embargo, se puede deducir de las propias palabras de estos informantes que su presencia, adaptada a los nuevos modelos socioeconómicos, sigue presente (matizable y acorde con las nuevas simbologías y funciones de poder/prestigio en cada sociedad local) en una división social desigual que continúa articulando estas sociedades locales. Así se desprende en referencias que encontramos al hablar de las tipologías de las casas, bodas y sistema de parentesco, evolución en los sistema organizativos de rituales y hermandades, tratamientos protocolarios en las relaciones interpersonales, etc.

La dependencia extrema como única fuente de la información textual aportada en cada epígrafe por los informantes seleccionados, hace que no siempre sean coherentes las conclusiones que podamos sacar. Aunque ello no menoscaba en absoluto la riqueza de información que nos transmite sus palabras, y su potencialidad como información base para un uso comparativo tanto en la evolución de los cambios sociales dentro de la propia comarca como en relación a otros lugares.

Lo que sí sorprende es la falta de otro material, no menos etnográfico y nos consta que 
existe en los archivos del autor, que hubiera ayudado a aclarar la información aportada y a aproximarse al conocimiento de la comarca para aquellos que la desconocen. Una sencilla tabla nos hubiera aportado los datos demográficos de las poblaciones que las componen y hacernos idea de sus dimensiones y papel que ocupan en plano geopolítico comarcal y en la voz de los informantes que las refieren; unos breves esquemas planimétricos darnos cuenta de la estructura básica de sus viviendas y aclarar la terminología con la que se conocen las diferentes dependencias y cualquier otra peculiaridad vinculada a las mismas. Pero sobre todo faltan fotografías, lo cual puede parecer un contrasentido si vemos que en la portada del texto aparecen a modo de composición simbólica los instrumentos básicos con los que un antropólogo aborda su trabajo de campo: cuaderno de campo, grabadora y cámara fotográfica. Únicamente en el capítulo introductorio hay antiguas fotografías, sacadas durante la labor de trabajo de campo, en varias de ellas aparece como testimonio de fe el propio autor. Apenas son 12, de ellas 3 están dedicadas a uno de sus comportamientos rituales más significativos, los auroros, y en alguna otra se puede entrever algún otro elemento relacionado con su arquitectura u oficios referenciados; pero en su mayor parte no tienen una finalidad "etnográfica" sino testimonial, nos dan cuenta de la interacción habida entre el etnógrafo (Javier Marcos) y sus informantes, lo que las hace coherentes con la finalidad del texto.

Pero no hay una sola imagen en el núcleo central del texto dedicado a la etnografía. Y no deja de ser contradictorio no recurrir a algunas imágenes precisamente para contrarrestar simbólicamente la propia imagen, valga la redundancia, de olvido y desconocimiento de la comarca de La Siberia. ¿Cómo son los paisajes tantas veces referenciados?, ¿las viviendas y calles de estas poblaciones?, ¿los santuarios que albergan sus imágenes y parajes que los acogen?, casi todo lo que se narra bien podría tener una imagen que lo visualice, ya sea mirando en el presente o recuperándola del pasado.

Para concluir, el tercer bloque que compone la obra serían los capítulos finales. En ellos se recoge el guion empleado en las entrevistas y un glosario terminológico. Los extensos contenidos del primero reflejan la ambición del proyecto, con una intencionalidad de realizar una etnografía que abarcara la totalidad de registros de la cultura tradicionalpopular de la comarca, pero que también nos recuerdan buena parte de las prioridades que, en el buen sentido de la palabra, caracterizaron los estudios de foklore de antaño y el anhelo de registrar antiguos saberes y prácticas culturales amenazadas. Etnografía y folklore se entremezclan, generando una imagen de comunidades/territorio igualitarista que dificulta entrever como las mismas preguntas y sus respuestas es posible que no sólo cambien en razón del factor tiempo, sino también por motivos relacionados con la posición social de los informantes e incluso de la distribución geográfica y experiencias 
compartidas en cada comunidad.

El otro capítulo de este bloque final constituye en mi opinión otra de las piezas claves del texto. Se trata de un extenso y elaborado "glosario" que supera con creces la finalidad y contenidos aclaratorios que usualmente se da a este término. En él encontramos buena parte de las explicaciones e interpretaciones comparativas que las mismas palabras tienen en diferentes localidades. Un extenso glosario cuyo léxico recoge y nos explica a qué se refieren los diversos términos empleados por los informantes en relación con las temáticas surgidas. Se registra por igual alocuciones, conceptos aplicados a determinados valores sociales, prácticas relacionadas con oficios y vida cotidiana, denominación de las diversas manifestaciones de la cultura material y los elementos que las componen, etc. Tal vez buena parte de estas explicaciones sucintas debieran haberse insertado en el texto, no solo para aclarar sus contenidos sino también para articular el propio discurso en muchos casos, reflejando la disparidad de usos y finalidades que unos mismos términos o valores sociales tienen según que contexto.

Según nos cuenta el autor, trabajo editado, de ahí también buena parte de lo dicho y los comentarios que hemos hecho, en ningún caso críticos con los contenidos aunque tal vez con las formas, no es sino la publicación del informe que en su día presento tras el año de trabajo realizado en 14 de las 17 poblaciones que conforman la comarca. Javier Marcos es un antropólogo extremeño pionero de esta disciplina en esta comunidad, amante de su tierra y buen conocedor de los entresijos de su cultura, como queda de manifiesto en una abundante y rigurosa bibliografía sobre muy diferentes temas de la cultura extremeña.

De ahí que tal vez también debiéramos cuestionarnos esta crítica benévola a las formas empleadas en este trabajo, según creemos no siempre acordes con una rigurosa interpretación antropológica. Las formas en que está desarrollado no vienen a ser sino el modo premeditado de un autor con sobrada experiencia como para haber declinado una interpretación más elaborada de estos resultados en aras de dejar el protagonismos a los informantes, al modo como se expresaron, y también al propio tiempo que recrean con sus palabras dando valor en sí al proceso de transformación en el que estaban inmersos. 